\title{
AOR
}

Selected Papers of \#AolR2021:

The 22nd Annual Conference of the Association of Internet Researchers Virtual Event / 13-16 Oct 2021

\section{SURVEILLANCE FOR INDEPENDENCE: DISCURSIVE FRAMEWORKS IN SMART CARE FOR DEMENTIA}

Christine Hine

University of Surrey

Payam Barnaghi

Imperial College London

\section{Introduction}

This paper examines the scenario of smart care, within which surveillance via Internet of Things is widely portrayed as a means to maintain the independence of those being monitored. Smart technologies promise a future in which the care needed by vulnerable people can be delivered at a distance, informed by remote sensing and by artificial intelligence used to identify problematic patterns in physiological readings and behavioural data. Innovations in this field aim to support people in living at home with conditions such as dementia, enabling distant carers to be alerted to changing patterns of activity and vital signs that may presage a worrying deterioration and thus to act in time to avert crises. Smart care at home is often positioned as preserving independence for longer, by averting emergency hospitalizations and delaying the need for a transition into residential care. Whilst there is an efficiency and cost-reduction pay-off to automation of care, there is also an aspiration that this kind of personalized monitoring could enhance care and offer better outcomes, by enabling people to both be supported but also maintain some autonomy.

\section{Background}

Concerns have been raised repeatedly about the ethics of smart technologies, with their potential to invade privacy and challenge human autonomy. Ethical principles for datadriven technologies have been widely discussed, with consensus centring on the need for artificial intelligence to be implemented in forms that assure beneficence, nonmaleficence, autonomy, justice and explicability (Floridi and Cowls 2019). There are, however, considerable challenges still in achieving practical mechanisms for implementation of these principles (Mittelstadt 2019). A sociological perspective allows us to understand ethics as an emergent everyday practice that resides not simply in technologies themselves or as abstract principles, but in the social relations that these 
technologies enact and develop meaning within (Pols, 2015). This paper arises from a collaborative project between a sociologist and a team implementing smart care for dementia, designed with this framing in mind. Later stages of the project will involve interviews with developers, healthcare professionals, people living with dementia and their carers to explore their diverse perspectives on ethical challenges and dilemmas across the lifetime of the implementation. This paper presents preparatory work exploring framing of smart care in the surrounding policy and commercial environment.

\section{Method}

This paper examines the promise of smart care through analysis of documentation from policy, from research and development settings and from marketing materials aimed at carers, people living with dementia and social care agencies in the UK (the documents analysed include the UK National Health Service long-term plan (https://www.longtermplan.nhs.uk/), the UK Al Council's Al Roadmap published in 2021 (https://assets.publishing.service.gov.uk/government/uploads/system/uploads/attachme nt_data/file/949539/AI_Council_Al_Roadmap.pdf), web materials from commercial services Canary Care (https://www.canarycare.co.uk/) and Howz (https://howz.com/) and from the NHS Al Lab NHSX (https://www.nhsx.nhs.uk/) and the TiHM smart care initiative (https://www.sabp.nhs.uk/TIHM). The analysis explored significant discursive framings in these documents concerning who cares for whom, what relationships are made explicit, what role is played by technology in the act of caring and what responsibilities are enacted when care becomes smart, conducting a fine detail coding of relevant sections of the documents and aggregating into broader themes relating to the framing of the relations of smart care.

\section{Key findings}

\section{Care as worry}

It is common for experiential accounts of caring for people to mention the worry that care entails (van Manen 2002). Care involves "an inherent duality of work and emotion" (Palacios 2020) and this is often particularly exacerbated by not being co-located all of the time with the person for whom one cares. This framing is common in the marketing of consumer-facing smart care solutions positioned as alleviating the need to worry. The monitoring carried out by smart care is predominantly framed as reassurance for the carer alongside reassurance for the person living with dementia that there will be help at times of need.

Knowledge deficits and care Within professional healthcare contexts, a framing of limitations imposed upon optimal care by knowledge deficits takes over from the emotional framing of worry. Patients are seen as coming too late to medical interventions and distance, lack of capacity and lack of co-presence are seen as creating knowledge deficits. Lack of knowledge is positioned as a limiting factor on providing optimal care and hence the monitoring offered by smart care becomes an ethical responsibility in the search for improved care

Problems of anticipation and uncertainty

A key aspect of the care situation for dementia is framed as not knowing what will happen, how the condition will progress and what short term, treatable problems may also arise. In this context of uncertainty, Al promises some insight into both present and possible futures. These insights may reshape the ethical duties felt 
by those caring in the present time and shift the extent to which they feel

empowered to take decisions on behalf of the person living with dementia.

\section{Conclusion}

The discourse of smart care offers an ethical justification of surveillance as providing a modicum of independence in a situation where one is already positioned as vulnerable. The prevalent discursive framings of smart care as a solution for worry, for knowledge deficits and for uncertainty raise their own ethical challenges, however. It is important to consider whether the promise of smart care is also accompanied by a sense of the agency and independence and the involvement in an active relational citizenship that is held as being so important for living well with dementia (Keyes, 2019). Surveillance and the Al-generated predictions that are built upon it could instead offer imperatives to action that may act against independence through an increased medicalization of everyday living. Smart care intervenes in a very fraught territory of decision-making for people living with dementia and their carers, where a balance between safety, autonomy, and assessment of capacity and best interests is often problematic. We need to know more about how people live with such systems and how these systems become a part of the complex relations of expertise, emotion and responsibility that pervade care. This will allow us to evaluate how far the discursive framing of smart care as identified above is mirrored in the actual experience of those cared-for and caring and where they see further ethical issues arising. Understanding how ethical issues are identified and managed in the implementation of smart care from the perspective of those involved may enrich principle-based ethical evaluation of smart care technologies.

\section{References}

Floridi, L., \& Cowls, J. (2019). A unified framework of five principles for Al in society. Harvard Data Science Review 1(1). doi: 10.1162/99608f92.8cd550d1

Keyes, S. E., Clarke, C. L., \& Gibb, C. E. (2019). Living with dementia, interdependence and citizenship: narratives of everyday decision-making. Disability \& Society, 34(2), 296-319. doi: 10.1080/09687599.2018.1528970

Mittelstadt, B. (2019). Principles alone cannot guarantee ethical Al. Nature Machine Intelligence, 1(11), 501-507. doi: 10.1038/s42256-019-0114-4

Palacios, J., Pérez, P., \& Webb, A. (2020). The experience of caring for an older relative in Chile: going beyond the burden of care. Ageing \& Society, 1-20.

doi:10.1017/S0144686X20001567

Pols, J. (2015). Towards an empirical ethics in care: Relations with technologies in health care. Medicine, Health Care and Philosophy, 18(1), 81-90. doi:10.1007/s11019014-9582-9

Van Manen, M. (2002). Care-as-worry, or "don't worry, be happy”. Qualitative Health Research, 12(2), 262-278. doi: 10.1177/104973202129119784 
Funding Preparation of this article was funded by APEX award APXIR1|201173 awarded by the British Academy, the Royal Academy of Engineering and the Royal Society and with generous support from the Leverhulme Trust. 